\title{
Activation of endoplasmic reticulum stress signaling pathway is associated with neuronal degeneration in MoMuLV-ts1-induced spongiform encephalomyelopathy
}

\author{
Hun-Taek Kim ${ }^{1}$, Kara Waters ${ }^{1}$, George Stoica ${ }^{1}$, Wenan Qiang ${ }^{2}$, Na Liu ${ }^{2}$, Virginia L Scofield ${ }^{2}$ \\ and Paul KY Wong ${ }^{2}$ \\ ${ }^{1}$ Department of Pathobiology, Texas A\&M University, College Station, TX, USA and ${ }^{2}$ Department of \\ Carcinogenesis, The University of Texas MD Anderson Cancer Center Science Park-Research Division, \\ Smithville, TX, USA
}

\begin{abstract}
Temperature-sensitive mutant of Moloney murine leukemia virus-TB (MoMuLV-ts1)-mediated neuronal death in mice is likely due to both loss of glial support and release of cytokines and neurotoxins from $t s 1$-infected glial cells. Cytotoxic mediators present in ts 1 -induced spongiform lesions may generate endoplasmic reticulum (ER) stress, which has been implicated in the pathogenesis of a variety of neurodegenerative diseases. We investigated whether ER stress signaling is involved in $t s 1$-mediated neuronal loss in the brain of infected mice. ts1-infected brainstems were found to show significant increases in phosphorylation of the double-stranded RNA-dependent protein kinase-like ER kinase and eukaryotic initiation factor 2- $\alpha$. In addition, increased expression of growth arrest DNA damage 153 (GADD153), glucose-regulated protein 78, and caspase-12 were accompanied by increases in processing of caspase-12 and its downstream target, caspase-3. All of these events are markers of ER stress. We observed that GADD153 and cleaved caspase-3 were present in degenerative neurons in the lesions of infected mice, but not in uninfected controls. Phosphorylated calmodulin-dependent protein kinase II- $\alpha$ was significantly increased, and was coexpressed with GADD153 in a large proportion of neurons undergoing early and advanced degenerative changes. Finally, neuronal degeneration in spongiform lesions was associated with increase in calcium $\left(\mathrm{Ca}^{2+}\right)$ accumulation in mitochondria. Together, these results suggest that $t s 1$ infection-mediated neuronal degeneration in mice may result from activation of ER stress signaling pathways, presumably initiated by perturbation of $\mathrm{Ca}^{2+}$ homeostasis. Our findings highlight the importance of the ER stress signaling pathway in ts 1 infection-induced neuronal degeneration and death.
\end{abstract}

Laboratory Investigation (2004) 84, 816-827, advance online publication, 19 April 2004; doi:10.1038/labinvest.3700104

Keywords: MoMuLV-ts1; ER stress; GADD153; CaMKII- $\alpha$; calcium; neuronal death; spongiform encephalomyelopathy

Moloney murine leukemia virus-TB (MoMuLV) is a type $\mathrm{C}$ retrovirus that induces $\mathrm{T}$-cell lymphomas in susceptible strains of mice. ${ }^{1}$ Its temperature-sensitive mutant $t s 1$ has a single point mutation in the envelope gene, which confers upon the virus the ability to cause loss of $\mathrm{T}$ cells and motor neurons in susceptible host strains. ${ }^{2-4} t s 1$ infection of the CNS causes a progressive neurodegenerative disease that

Correspondence: Dr Professor G Stoica, DVM, PhD, Department of Pathobiology, Texas A\&M University, College Station, TX 77843, USA.

E-mail: gstoica@cvm.tamu.edu

Received 17 November 2003; revised and accepted 2 March 2004; published online 19 April 2004 morphologically manifests as spongiform polioencephalomyelopathy. ${ }^{5}$ ts1-mediated neuronal degeneration is likely due to loss of glial support and release of proinflammatory cytokines and neurotoxins such as tumor necrosis factor- $\alpha$ (TNF- $\alpha$ ), interleukin-1 (IL-1), and nitric oxide (NO) from surrounding $t s 1$-infected glial cells. ${ }^{5-7}$

In brainstems of ts1-infected mice, neurons display apoptosis, vacuolization and inclusion bodies. ${ }^{5,8}$ These histopathological hallmarks have been associated with animal and human neuronal diseases such as human immunodeficiency virus (HIV)-induced neurodegenerative disease, ${ }^{9}$ Parkinson's disease, ${ }^{10}$ amyotrophic lateral sclerosis, ${ }^{11}$ motor neuronopathy, ${ }^{12}$ and transmissible 
spongiform encephalopathy. ${ }^{13}$ However, there have been no detailed in vivo investigations regarding the molecular mechanism(s) involved in neuronal loss in ts1-induced encephalomyelopathy.

The ER is a principal site for protein synthesis and folding, and also serves as a cellular storage site for $\mathrm{Ca}^{2+}$. ER homeostasis is sensitive to a variety of different stimuli, such as glucose deprivation, perturbation of intracellular and extracellular $\mathrm{Ca}^{2+}$ concentration, and exposure to free radicals. Such conditions can trigger ER stress signals that provoke three functionally distinct responses. ${ }^{14-16}$ The first one is upregulation of genes encoding ER chaperone proteins such as glucose-regulated protein 78 (Bip/GRP78). The second is translational attenuation by phosphorylating the double-stranded RNA-dependent protein kinase-like ER kinase (PERK) and eukaryotic initiation factor $2-\alpha($ eIF2- $\alpha)$. Unless those two previous adaptive responses are sufficient, a cell death program is activated by transcriptional activation of the gene for GADD153/CHOP (CCAAT/enhancer-binding protein (C/EBP)-homology protein) and by cleavage activation of the ER-associated caspase-12. ${ }^{17-20}$ Prolonged ER stress is a primary component in the neuropathology of a wide variety of neurological disorders. ${ }^{16,21}$

Recent evidence suggests that either TNF- $\alpha$ or NO causes the ER to release $\mathrm{Ca}^{2+}$, leading to activation of ER-stress signaling pathways and cell death in various types of cells. ${ }^{22-24}$ ER stress activates the mitochondrial apoptosis pathway. ${ }^{25,26}$ The release of proapoptotic factors from mitochondria is triggered by the proapoptotic Bcl-2 family members such as Bax. ${ }^{26,27}$ ts 1 infection of glial cells secretes neurotoxic products such as TNF- $\alpha$ and NO, and impair proteasome activity in neighboring neurons. ${ }^{6-8}$ We have shown that the expression level of Bax is increased in neuronal cells in brainstems of $t s 1$-infected mice. ${ }^{28}$ In addition, our preliminary studies show that mitochondria of degenerating neurons have damaged cristae and $\mathrm{Ca}^{2+}$ deposits. All of these connected events may cause ER stress in neurons, leading to neuronal death.

The aim of this study is to elucidate the causes of neuronal death in the ts1-infected brainstems, with emphasis on ER stress signaling pathways. We report here that $t s 1$ infection causes ER stress, leading to neuronal death, presumably initiated by interference with $\mathrm{Ca}^{2+}$ homeostasis. These findings highlight the involvement of the ER stress signaling pathway in retroviral infection-induced neuronal cell degeneration and death in vivo.

\section{Materials and methods}

\section{Reagents and Antibodies}

Sodium orthovanadate $\left(\mathrm{Na}_{3} \mathrm{VO}_{4}\right)$, sodim $\beta$-glycerophosphate, sodium fluoride $(\mathrm{NaF})$, dithiothreitol
(DTT), and phenylmethylsulfonyl fluoride (PMSF) were purchased from Sigma Chemical Company (St Louis, MO, USA). Leupeptin, pepstatin, and aprotinin were purchased from Boehringer Mannheim (Indianapolis, IN, USA). Iodoacetamide (an isopeptidase inhibitor) was obtained from Fluka Chemical Corp. (Milwaukee, WI, USA).

Goat IgG antibody against gPr80 ${ }^{\text {env }}$ has been described previously., ${ }^{4,5}$ Rabbit IgG antibodies against phosphospecific eIF2- $\alpha$ and PERK, caspase3 , cleaved caspase-3, and caspase-12 were purchased from Cell Signaling Technology (Beverly, MA, USA). Rabbit IgG antibodies against GADD153/ CHOP, phosphorylated calmodulin kinase II- $\alpha$ (CaMKII- $\alpha$ ), and goat IgG antibody against Bip/GRP78 were from Santa Cruz Biotechnology (Santa Cruz, CA, USA). Rabbit IgG antibody against glial fibrillary acidic protein (GFAP) was purchased from DAKO (Carpinteria, CA, USA). Monoclonal mouse IgG antibody against $\beta$-actin was purchased from Sigma.

\section{Virus}

ts1 virus was propagated in the thymus-bone marrow cell line TB. Virus titers were determined using a modified direct focus assay in $15 \mathrm{~F}$ cells, which are a murine sarcoma-positive, leukemianegative cell line, as described. ${ }^{29}$

\section{Animals and Virus Infection}

FVB/N mice were obtained from Taconic Farms (Germantown, NY, USA). Mice were maintained in sterilized microisolators and supplied with autoclaved food and water ad libitum. Newborn FVB/N mice were inoculated intraperitoneally with $0.1 \mathrm{ml}$ of $t s 1$ viral suspension containing $10^{6}-10^{7}$ infectious units $/ \mathrm{ml}$, as described previously, ${ }^{8}$ while control mice were inoculated with medium only. The mice were observed daily for signs of paralysis, and were killed at 20 and 25 days post-infection (dpi). We have determined previously that histologically detectable neuronal loss is not significant at $20 \mathrm{dpi}$, but is evident at $25 \mathrm{dpi}{ }^{6,8}$ This experimental protocol was approved by the Texas A\&M University Institutional Animal Care and Use Committee.

\section{Tissue Processing}

For histopathology and immunohistochemistry, ts1infected $(n=5)$ and control $(n=5)$ mice were anesthetized using an intraperitoneal injection of pentobarbital $(150 \mathrm{mg} / \mathrm{kg})$ and perfused with $10 \%$ buffered formalin, using a peristaltic pump. After a $12 \mathrm{~h}$ fixation, the brain segments were separated for further processing. For RT-PCR and Western blotting analyses of mRNAs and proteins in the brainstem, 
control $(n=4)$ and ts1-infected $(n=4)$ mice were killed, their brains removed, and the brainstem tissues snap-frozen in liquid nitrogen and stored at $-80^{\circ} \mathrm{C}$.

\section{Semiquantitative RT-PCR Analyses}

Total RNA was isolated using the Trizol reagent (Invitrogen, Carlsbad, CA, USA), as described previously. $^{30}$ Reverse transcription was performed using the ultra-HF RT-PCR system kit (Strategene, La Jolla, CA, USA). Briefly, $1 \mu \mathrm{g}$ of DNAase-treated total RNA was mixed with oligo (dT) primers and dNTPs. Synthesized cDNA was amplified by a standard PCR protocol using Taq polymerase and mouse specific primers for gPr80 ${ }^{\text {env }}$ (forward: $5^{\prime}$-ATA ACA ATC TCA CCT CTG ACC AGG-3'; reverse: 5'GAG CAG AGG TAT GGT TGG AGT AGG-3'), GADD153/CHOP (forward: 5'-TGC CTT TCA CCT TGG AGA CG-3'; reverse: $5^{\prime}$-CCA TAG AAC TCT GAC TGG AAT CTG G-3'), Bip/GRP78 (forward: 5'CCA CTA ATG GAG ATA CTC ACC TGG G-3'; reverse: 5'-GTA AGG GGA CAC ACA TCA AGC AG3'), caspase-12 (forward: 5'-GGA GGT AAA TGC TGG ATT GGC-3'; reverse: $5^{\prime}$-GCT TTT TGT TTC GGT GCT TCA C-3'), and caspase-3 (forward: $5^{\prime}$ GAG CAC TGG AAT GTC ATC TCG C-3'; reverse: $5^{\prime}$ AAG CAT ACA GGA AGT CAG CCT CC-3'). Parallel amplifications with primers for $\beta$-actin cDNA (forward: 5'-ATG TAC GTA AGC CAT CCA GGC-3'; reverse: $5^{\prime}$-AAG GAA GGC TGG AAA AGA GC-3') were performed. The numbers of cycles (between 21 and 24) giving the linear range and annealing temperatures (between 56.0 and $58.3^{\circ} \mathrm{C}$ ) were adjusted depending on the genes amplified. Reaction products were electrophoresed on $1.5 \%$ agarose gels. Band intensities were analyzed using a densitometer (Model GS-690; Bio-Rad, Hercules, CA, USA) equipped with the Multi-Analyst software program (Version 1.01; Bio-Rad). For quantification, the densities of the signals were normalized to that for $\beta$-actin.

\section{Tissue and Cell Extracts}

Brainstem tissue lysates were prepared by homogenization of frozen tissues in 10 volumes of lysis buffer containing $50 \mathrm{mM}$ Tris-HCl (pH 7.9), $150 \mathrm{mM}$ $\mathrm{NaCl}, 1 \mathrm{mM}$ EDTA, $1 \mathrm{mM} \mathrm{Na} \mathrm{VO}_{4}, 30 \mathrm{mM}$ sodium $\beta$ glycerophosphate, $50 \mathrm{mM} \mathrm{NaF}, 10 \mathrm{mM}$ iodoacetamide, $1 \mathrm{mM}$ DTT, $1 \%$ Nonidet P-40, $1 \mathrm{mM} \mathrm{PMSF}$, $10 \mu \mathrm{g} / \mathrm{ml}$ pepstatin, $10 \mu \mathrm{g} / \mathrm{ml}$ leupeptin, and $5 \mu \mathrm{g} / \mathrm{ml}$ aprotinin. The lysates were cleared by centrifugation at $13,000 \mathrm{~g}$ at $4^{\circ} \mathrm{C}$ for $20 \mathrm{~min}$, and the supernatants kept frozen at $-80^{\circ} \mathrm{C}$. The protein content of the lysates was determined using the Bradford Assay (Bio-Rad), with bovine serum albumin as the standard.

\section{Western Blotting}

Proteins (20-50 $\mu \mathrm{g})$ were separated by $6-12 \%$ sodium dodecyl sulfate-polyacrylamide gel electro- phoresis (SDS-PAGE), and then transferred to nitrocellulose membranes (Schleicher and Schuell, Keene, NH, USA). The membranes were incubated for $1 \mathrm{~h}$ in blocking buffer $(20 \mathrm{mM}$ Tris-HCl buffered saline containing $5 \%$ nonfat milk powder and $0.1 \%$ Tween 20) at room temperature, and then probed with appropriate antibodies in blocking buffer overnight at $4^{\circ} \mathrm{C}$. Normal mouse, rabbit, or goat IgGs at the same dilutions were used as controls. The blots were incubated with appropriate secondary IgG-peroxidase conjugates (1:10,000 dilution; Kirkegaard Perry Laboratories, Gaithersburg, MD, USA), and developed using the enhanced chemiluminescence (ECL) method (Amersham Life Science, Arlington Heights, IL, USA). After imaging, the blots were stripped and reincubated with a mouse monoclonal anti- $\beta$-actin antibody to confirm equal protein loading. Densitometric analysis of autoradiographs was performed using a densitometer as described above.

\section{Immunohistochemistry}

Paraffin-embedded sections $(5 \mu \mathrm{m})$ were first deparaffinized and were then subjected to an antigenretrieval protocol, in which sections were heated in $10 \mathrm{mM}$ citrate buffer ( $\mathrm{pH}$ 6.0). for $10 \mathrm{~min}$, blocked with $5 \%$ normal serum in Tris-buffered saline (TBS; $100 \mathrm{mM}$ Tris, $150 \mathrm{mM} \mathrm{NaCl}, \mathrm{pH}$ 7.4), and then incubated overnight at $4{ }^{\circ} \mathrm{C}$ with primary antibodies at a dilution of 1:100. After washing, sections were incubated with biotin-conjugated secondary IgG, and then treated with reagents from a Vecta-Elite streptavidin-peroxidase kit with a benzidine substrate for color development. For double immunostaining, sections were pretreated with rabbit anti-GADD153/CHOP IgG as described above. Sections were then blocked with $5 \%$ normal goat or rabbit serum in TBS, after which the tissue sections were incubated with either rabbit anti-GFAP, cleaved caspase-3, or phosphorylated-CaMKII- $\alpha$ antibody at a dilution of 1:100 overnight at $4^{\circ} \mathrm{C}$. After incubation with secondary antibodies, sections were treated with an alkaline phosphataseavidin-biotin substrate and with red chromagen (Vector red; Vector Laboratories) for color development. Sections were counterstained with diluted hematoxylin. Sections without primary antibodies were similarly processed to control for binding of the secondary antibodies. On control sections, no specific immunoreactivity was detected.

\section{Ultrastructural Localization of $\mathbf{C a}^{2+}$}

The oxalate-pyroantimonate procedure was used to visualize the subcellular distribution of $\mathrm{Ca}^{2+}$ in cells from mouse brainstems, as previously described. ${ }^{31}$ At $20 \mathrm{dpi}$, control $(n=3)$ and ts1infected mice $(n=3)$ were anesthetized with pentobarbital (150 mg/kg, intraperitoneal injection), and 
perfused with a solution containing $2 \%$ paraformaldehyde, $2 \%$ glutaraldehyde and $90 \mathrm{mM}$ potasium oxalate ( $\mathrm{pH} 7.4)$ and kept overnight at $4^{\circ} \mathrm{C}$ in the same solution. Brainstems were removed and washed for $15 \mathrm{~min}$ in $7.5 \%$ sucrose containing $90 \mathrm{mM}$ potassium oxalate and then postfixed in a mixture of $1 \%$ osmium tetroxide and $2 \%$ potassium pyroantimonate in $0.01 \mathrm{~N}$ acetic acid (pH 7.4) for $2 \mathrm{~h}$. Ultrathin sections were stained with $0.5 \%$ uranyl acetate and $0.4 \%$ lead citrate and examined with a Zeiss EM 10 electron microscope. The specificity of
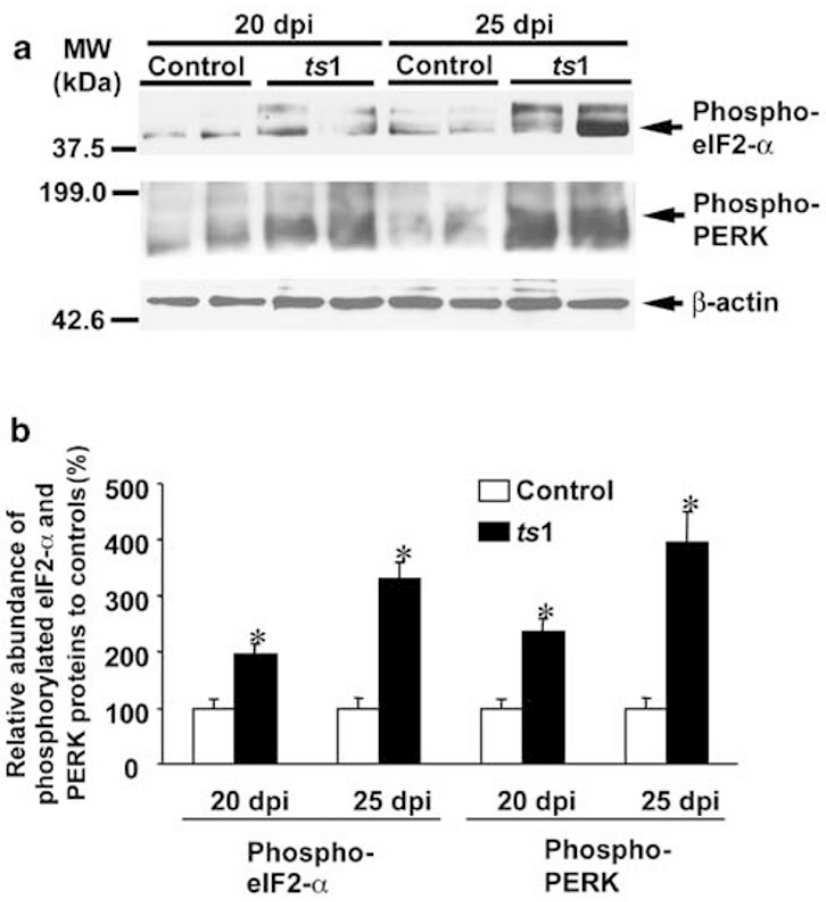

C

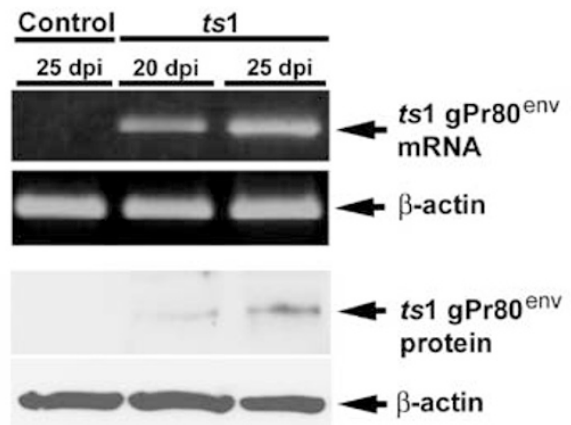

Figure 1 Increased phosphorylation of eIF2- $\alpha$ and PERK in $t s 1-$ infected brainstems. (a) Representative Western blots showing levels of phospho-eIF2- $\alpha$ and -PERK and in control and ts1infected brainstems at 20 and 25 dpi. (b) Quantitative analyses of levels of phospho-eIF2- $\alpha$ and -PERK in control and ts1-infected brainstems at 20 and $25 \mathrm{dpi}$. The results shown in the histogram are the mean $+\mathrm{s} . \mathrm{d}$. for tissues from four control and four ts1infected mice. ${ }^{*}$ Significantly different from controls $(P<0.01)$. (c) Representative photographs of semiquantitative RT-PCR and Western blots showing levels of viral envelope gPr80 ${ }^{\text {env }}$ mRNA and protein in control and ts1-infected brainstems at 20 and 25 dpi. the cytochemical reaction was tested by treating mounted ultrathin sections with $3 \mathrm{mM}$ ethylene glycol bis(b-aminoethylether)-N,N'-tetraacetic acid (EGTA) at $60^{\circ} \mathrm{C}$ for $1 \mathrm{~h}$. EGTA treatment, in turn, was controlled by incubation of sections for $1 \mathrm{~h}$ at $60^{\circ} \mathrm{C}$ in distilled water.

\section{Statistical Analysis}

Data obtained from densitometric analyses of RTPCR and Western blots were analyzed by Student's $t$-test. $P$-values of $<0.05$ were considered as statistically significant.

a
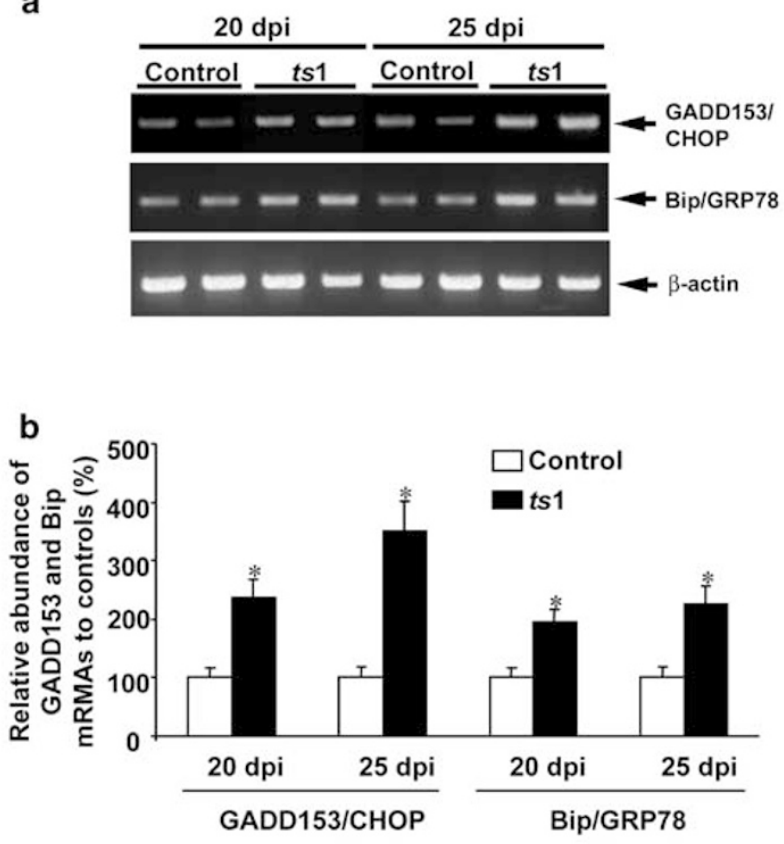

C

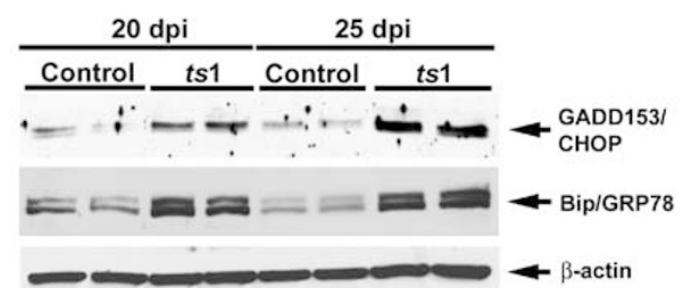

Figure 2 Induction of GADD153/CHOP and Bip/GRP78 in brainstems of $t$ s1-infected mice. (a) Representative photographs of semiquantitative RT-PCR analyses for GADD153/CHOP and Bip/GRP78 mRNAs in control and ts1-infected brainstems at 20 and 25 dpi. (b) Quantitative analysis of GADD153/CHOP and Bip/ GRP78 mRNA levels in control and ts1-infected brainstems. (c) Representative Western blots showing levels of GADD153/CHOP and Bip/GRP78 proteins in control and ts1-infected brainstems. $\beta$-Actin served as a loading control. The results shown in the histogram are the mean \pm s.d. for tissues from four control and four ts1-infected mice. *Significantly different from controls $(P<0.01)$. 

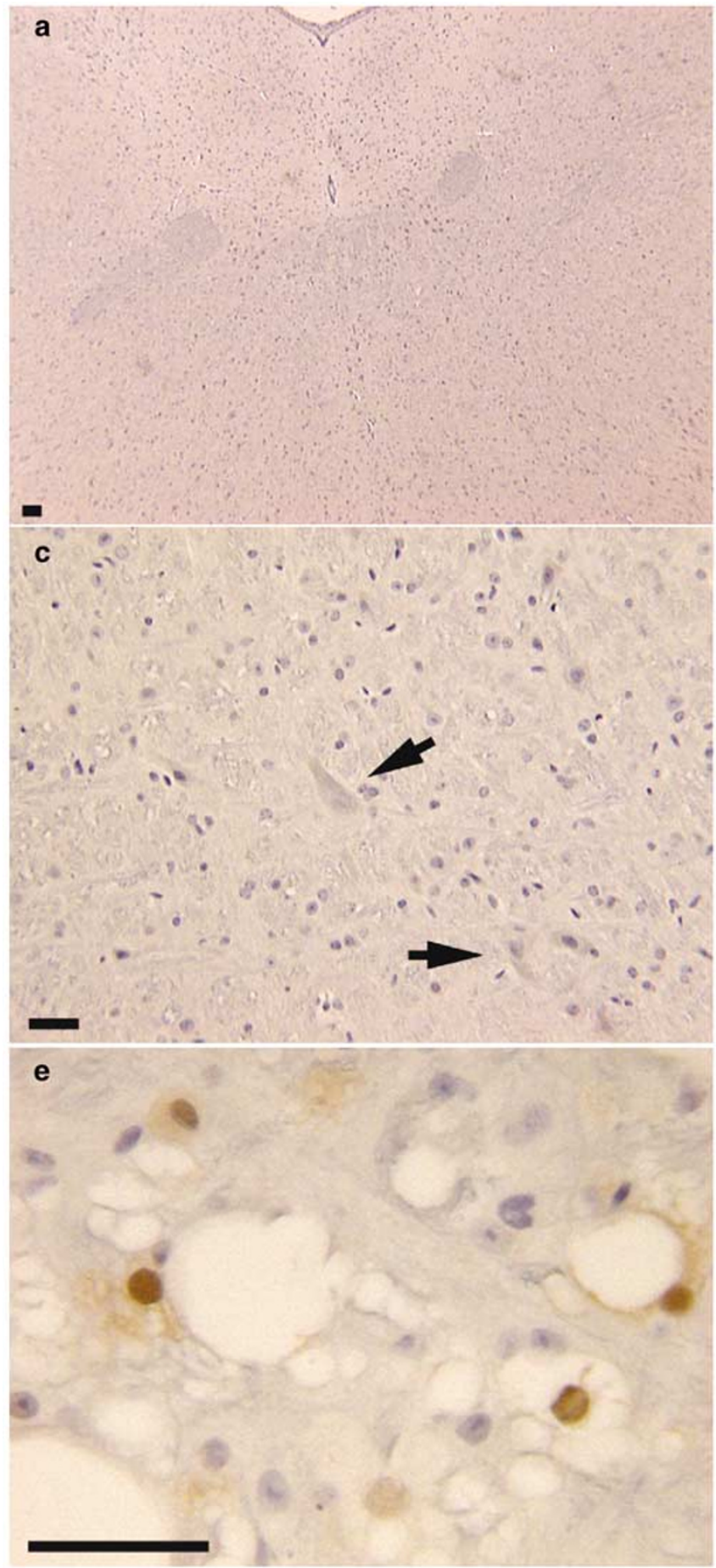

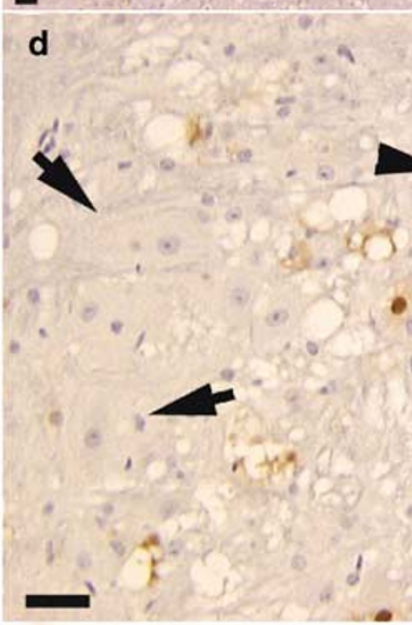

f

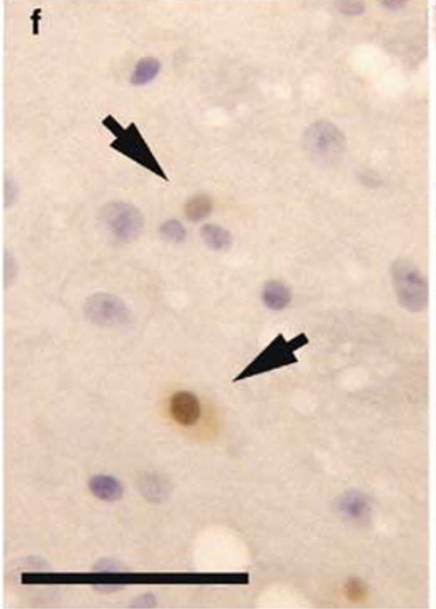

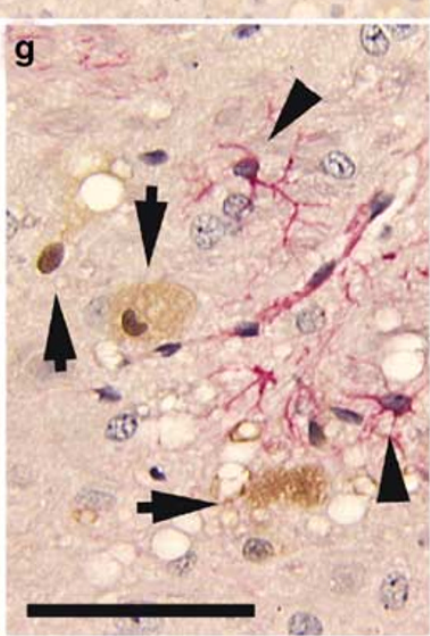

Figure 3 Increased expression of GADD153/CHOP protein in neurons of brainstems of ts1-infected mice. (a) GADD153/CHOP immunoreactivity (brown) in the brainstem from a control mouse. (b) GADD153/CHOP immunoreactivity in neurons of ts1-infected brainstem at 25 dpi. (c) Higher magnification view of the glial and neuronal cells in panel (a). Note the absent or very weak staining in neurons (arrows). (d) Higher magnification views of the boxed area in panel (b). Note the strong staining in neurons undergoing degenerative changes such as vacuolization (arrowheads) and the absence of immunoreactivity in neurons with normal appearance (arrows). (e) Higher magnification views of the boxed area in panel (d). (f) GADD153/CHOP immunoreactivity in neurons of $t s 1$-infected brainstem in early stage (at $20 \mathrm{dpi}$ ). Note the strong cytoplasmic and nuclear staining in neurons without morphologic changes (arrows). (g) Double immunostaining for GADD153/CHOP (brown) and GFAP (red) in ts1-infected brainstem (at 20 dpi). Note the absence of GADD153/CHOP immunoreactivity in astrocytes showing GFAP immunoreactivity (arrowheads), alongside strong GADD153/CHOP staining in neurons (arrows). Bars indicate $200 \mu \mathrm{m}$. 


\section{Results}

Activation of Upstream Regulators of ER Stress Signaling Pathway in Brainstems of ts1-infected Mice

To determine whether $t s 1$ infection causes ER stress in the brainstem, we first examined whether PERK and eIF2- $\alpha$, two major upstream transducers of ER stress signaling pathways, undergo phosphorylation. ${ }^{14}$ Phosphorylated eIF2- $\alpha$ in ts1-infected brainstems was increased 2.0- and 3.3-fold at 20 and 25 dpi, respectively, compared to controls (Figure1a and $\mathrm{b} ; P<0.01)$. Phosphorylated PERK in ts1infected brainstems was increased 2.3- and 3.8-fold at 20 and $25 \mathrm{dpi}$, respectively, compared to controls (Figure1a and b; $P<0.01$ ). To ascertain whether phosphorylation of PERK and eIF2- $\alpha$ is correlated with viral infection in brainstems, we determined the amounts of $t s 1$ viral envelope gPr $80^{\text {env }}$ mRNA and protein in brainstems. The expression of gPr80 ${ }^{\text {env }}$ mRNA and protein was increased in $t s 1$ infected mice in a time-dependent manner (Figure 1c). This result is consistent with those reported previously. ${ }^{4,32}$

\section{Induction of ER Stress-associated Genes in Brainstems} of $t s 1$-infected Mice

To determine whether phosphorylation of PERK and eIF2- $\alpha$ is accompanied by upregulation of ER stressassociated genes, GADD153/CHOP and GRP78, semiquantitative RT-PCR was used to compare amounts of GADD153/CHOP and Bip/GRP78 mRNAs in brainstems of control and ts1-infected mice (Figure 2a). Figure 2b shows that $t s 1$ infection induced 2.4- and 3.5-fold increases in GADD153/ CHOP mRNA at 20 and $25 \mathrm{dpi}$, respectively, compared to controls $(P<0.01)$. Bip/GRP78 mRNA increased 2.0- and 2.3-fold at 20 and $25 \mathrm{dpi}$ $(P<0.01)$, respectively, compared to controls. The pattern of increase in GADD153/CHOP and Bip/ GRP78 proteins was consistent with the increases in GADD153/CHOP and Bip/GRP78 mRNAs (Figure 2c).

\section{Increased Expression of GADD153/CHOP in Neurons} Showing Degenerative Changes

Immunostaining for GADD153/CHOP was performed to localize GADD153/CHOP in infected brainstem. Figure 3 shows that GADD153/CHOP were virtually absent in neurons and glial cells of control mice (Figure 3a and c), but abundant in neurons in ts1-infected brainstems (Figure $3 \mathrm{~b}$ and d). Notably, immunoreactivity was evident in both intact and visibly damaged neurons showing swelling, cytoskeletal collapse, vacuolization, and disintegration of nuclear and cytoplasmic membrane structures in the early and late stages of disease progression (Figure $3 \mathrm{e}$ and f). Double immunostaining for GADD153/CHOP and GFAP showed astrocytes in affected areas to be negative for GADD153/CHOP (Figure 3g).

\section{Activation of Caspase-12 and -3 Pathways in ts1-infected Brainstems}

In response to ER stress, caspase-12 specifically cleaves and activates effector caspases such as caspase- $3{ }^{20,33,34}$ Figure $4 \mathrm{a}$ and $\mathrm{b}$ show that brainstem tissues from ts1-infected mice had significantly higher levels of cleaved forms of caspase-12 (approximately $35-39 \mathrm{kDa}$ ) and caspase-12 than those from uninfected controls at 20 and $25 \mathrm{dpi}$ $(P<0.01)$. Figure $4 \mathrm{a}$ and $\mathrm{b}$ show that ts1-infected brainstem tissues also contained more cleaved caspase- 3 at 20 and $25 \mathrm{dpi}(P<0.01)$, being associated with decrease in amounts of caspase- 3 at

a
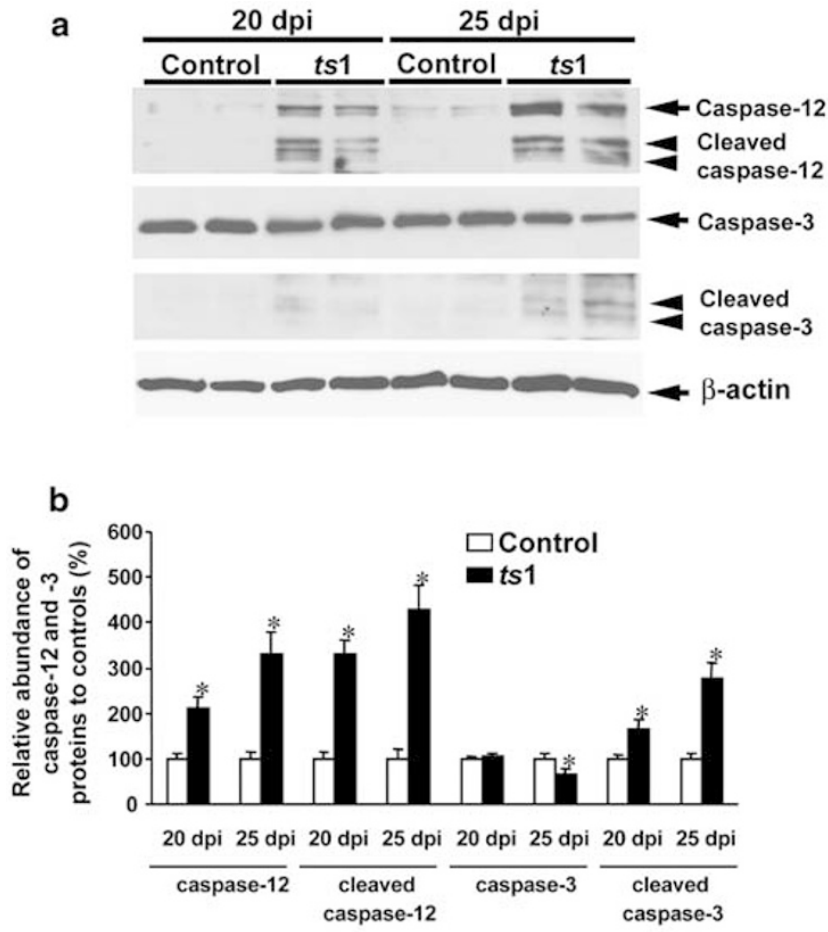

C

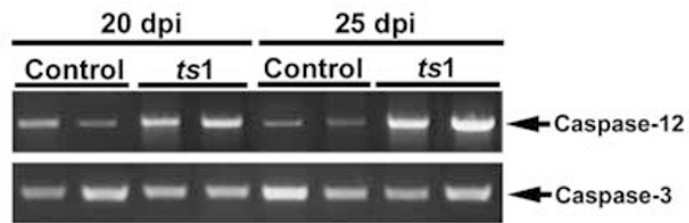

Figure 4 Expression of caspase-12 and -3 in brainstems of control and $t$ 1-infected mice. (a) Representative Western blots showing levels of caspase-12 and cleaved caspase-12, caspase-3, and cleaved caspase- 3 proteins in control and ts1-infected brainstems at 20 and 25 dpi. $\beta$-Actin acted as a loading control. (b) Quantitative analyses of levels of caspase-12, cleaved caspase12 , caspase-3, and cleaved caspase-3 proteins in control and ts1infected brainstems. The results shown in the histogram are the mean \pm s.d. for tissues from four control and four ts1-infected mice. *Significantly different from controls $(P<0.01)$. (c) Representative photographs of semiuantitative RT-PCR analyses for caspase-12 and -3 mRNAs in control and ts1-infected brainstems. 


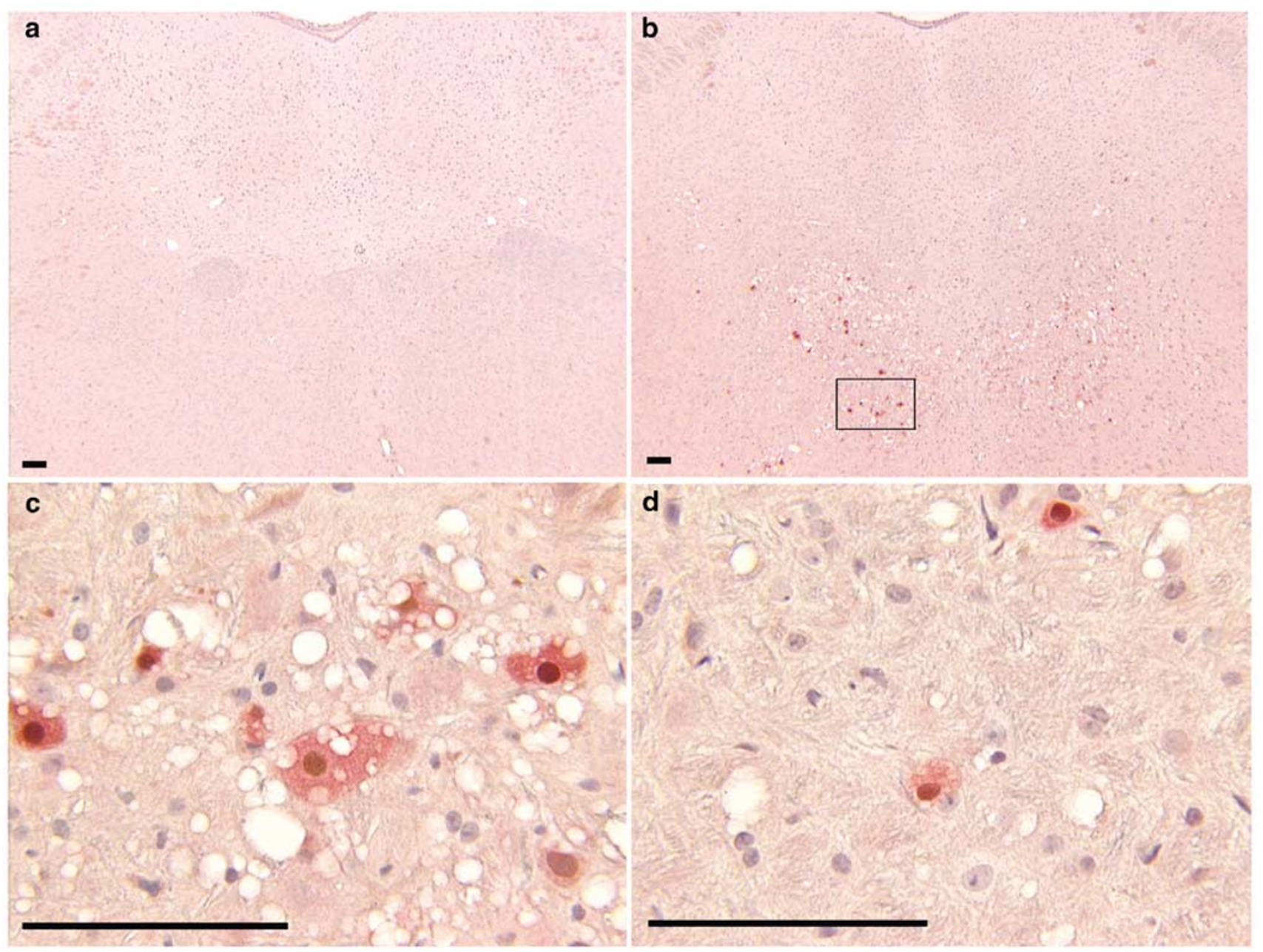

Figure 5 Colocalization of GADD153/CHOP and cleaved caspase-3 in neurons in brainstem section from ts1-infected mice. (a) Double immunostaining for GADD153/CHOP and cleaved caspase-3 in brainstem from a control mouse. (b) Double immunostaining to GADD153/CHOP (brown, nuclei) and cleaved caspase-3 (red, cytoplasm) in neurons undergoing degenerative changes in ts1-infected brainstem at 25 dpi. (c) Higher magnification views of the boxed area in panel (b). (d) Double immunostaining for GADD153/CHOP (brown, nuclei) and cleaved caspase-3 (red, cytoplasm) in neurons with normal appearance in ts1-infected brainstem at 20 dpi. Bars indicate $200 \mu \mathrm{m}$.

25 dpi $(P<0.01)$. As shown in Figure 4c, levels of caspase-12 mRNA were consistent with changes in amounts of caspase-12 protein (immunoblotting results in Figure $4 \mathrm{a}$ and b) at the corresponding time points. In contrast, levels of caspase-3 mRNA in ts1-infected brainstems were not significantly different from ones of uninfected controls.

\section{Coexpression of Cleaved Caspase-3 with GADD153/ CHOP in Neurons Undergoing Degenerative Changes}

To determine whether increased GADD153/CHOP protein levels occur together with cleavage of caspase-3, double immunostaining for GADD153/ CHOP and cleaved caspase-3 was performed (Figure 5). While no immunoreactivity for either GADD153/CHOP or cleaved caspase-3 was evident in brainstem neurons of control mice (Figure 5a), most of the neurons positive for cleaved caspase-3 immunostaining had moderate to strong nuclear GADD153/CHOP immunoreactivity at 20 and $25 \mathrm{dpi}$ (Figure $5 \mathrm{~b}-\mathrm{d}$ ).

\section{Phosphorylation of CaMKII- $\alpha$ is Increased in Brainstems of ts1-infected Mice and Correlated with Induction of GADD153/CHOP in Neurons}

Perturbation of $\mathrm{Ca}^{2+}$ homeostasis can elicit ER stress. ${ }^{35-37}$ One of the target kinases activated by intracellular $\mathrm{Ca}^{2+}$ increase is CaMKII. ${ }^{38,39}$ Therefore, we examined whether phosphorylation of neuronspecific CaMKII- $\alpha$ is increased in brainstems of ts1-infected mice. As shown in Figure 6a and b, phosphorylated CaMKII- $\alpha$ was increased 2.9- and 5.1 -fold in ts1-infected brainstems at 20 and $25 \mathrm{dpi}$, respectively, compared to controls $(P<0.01)$. Immunostaining for phosphorylated CaMKII- $\alpha$ showed that neurons with degenerative changes in 
a
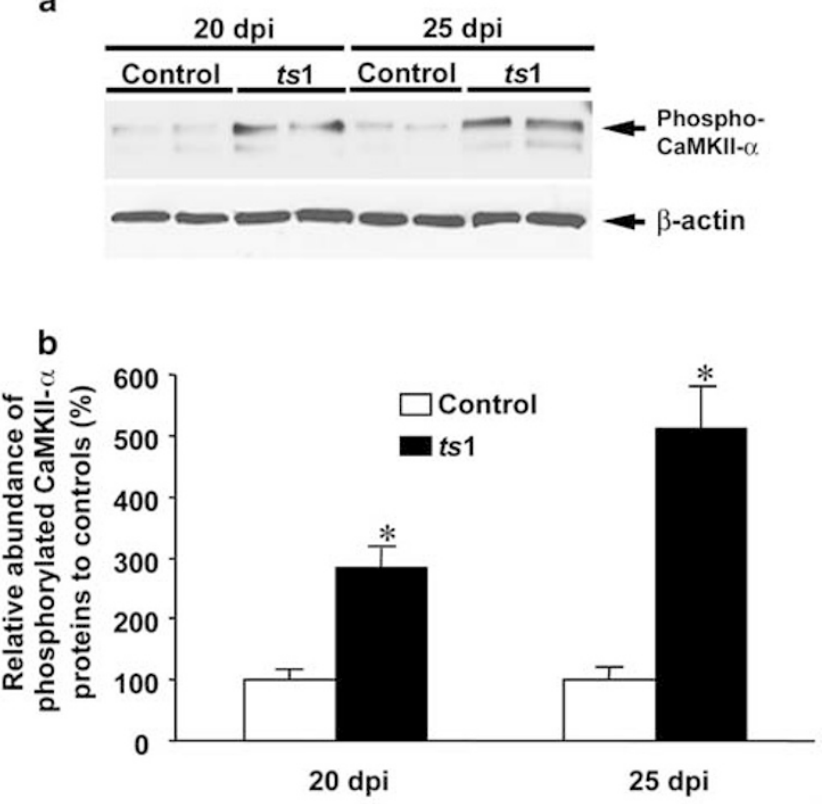

Figure 6 Increased expression of phosphorylated CaMKII- $\alpha$ in brainstems of $t s 1$-infected mice. (a) Representative Western blots showing levels of phosphorylated CaMKII- $\alpha$ (p-CaMKII- $\alpha)$ in control and ts1-infected brainstems at 20 and $25 \mathrm{dpi}$. $\beta$-actin served as a loading control. (b) Quantitative analysis of levels of p-CaMKII- $\alpha$ in control and ts1-infected brainstems. The results shown in the histogram are the mean \pm s.d. for tissues from four control and four ts1-infected mice. * Significantly different from controls $(P<0.01)$

ts1-infected brainstems showed moderate to strong cytoplasmic staining for phosphorylated CaMKII- $\alpha$ (Figure 7b and d), compared to controls (Figure 7a and $\mathrm{c})$. Most $(>95 \%)$ of neurons positive for immunoreactive GADD153/CHOP were also positive for phosphorylated CaMKII- $\alpha$ (Figure 7e and f). We used transmission electron microscopy to determine whether intracellular $\mathrm{Ca}^{2+}$ increase is involved in early development of neuronal degeneration. As shown in Figure $7 \mathrm{~h}$, increased intracellular $\mathrm{Ca}^{2+}$ was illustrated by cytochemical staining for $\mathrm{Ca}^{2+}$ deposits in damaged mitochondria of neurons at early stage, compared to control (Figure 7g).

\section{Discussion}

The present study shows that ts 1 infection triggers activation of ER stress signaling pathways in the brainstem, as evidenced by increases in phosphorylation of PERK and eIF2- $\alpha$, induction of GADD153/ CHOP and GRP78, and activation of the ERassociated caspase-12. The concomitant increases in GADD153/CHOP, cleaved caspase-3, phosphorylated CaMKII- $\alpha$, and intracellular $\mathrm{Ca}^{2+}$ in neurons implicate ER stress following intracellular $\mathrm{Ca}^{2+}$ increase in mechanisms leading to neurodegeneration in ts1-infected brainstems. Induction of these
ER stress markers is correlated temporally with increases in viral burden and noxious cytokines, neuronal loss, and the development of neuroclinical signs in infected animals. . $^{4,6,8,32}$

Particularly relevant to the present work are two recent studies describing roles of ER stress in neurodegeneration. Hetz et $a{ }^{40}$ demonstrated that ER stress and caspase-12 mediate neurotoxicity of pathological prion protein. Dimcheff et $a l^{41}$ also showed that another murine neurotropic virus, FrCas $^{\mathrm{E}}$, triggers ER stress in the brainstems leading to spongiform degeneration. Together with these recent publications, our results strongly support the idea that spongiform neurodegeneration is likely to be mediated by ER stress.

GADD153/CHOP has emerged recently as a ubiquitous regulator of neuronal death. ${ }^{42}$ Induction of GADD153/CHOP appears to be an early event contributing to neuronal dysfunction and death in ts1-infected brainstems. This conclusion is based on the observation that increased expression and nuclear translocation of GADD153/CHOP is evident early in the disease course in neurons without morphological changes and becomes more pronounced in neurons showing advanced degenerative changes in late stages.

What is the role of GADD153/CHOP in neuronal degeneration in ts1-infected brainstems? A previous study showed that GADD153/CHOP is a negative regulator of Bcl-2 expression. ${ }^{43}$ Also, GADD153/ CHOP may sensitize cells to noxious stimuli by inducing the expression of pro-apoptotic genes such as Bax and caspases. ${ }^{44,45}$ It is noteworthy that the Bcl-2 protein levels in brainstems of ts1-infected mice are decreased at late stages of disease (data not shown). However, the precise pro-cell-death targets of GADD153/CHOP transcription factor during $t s 1$ infection of the brainstem remain to be identified.

In contrast to GADD153/CHOP, the chaperone GRP78 promotes protein folding and thus attenuates cellular death under stress conditions. ${ }^{46,47}$ While GRP78 was found to be increased in early and late stages of disease in ts1-infected brainstems, there was no progressive increase in GRP78 mRNA and protein from 20 to $25 \mathrm{dpi}$. Similarly, previous studies with $\mathrm{FrCas}^{\mathrm{E}}$ - or scrapie-infected mice have shown that there is no clear correlation between the expression of GRP78 and the development of ER stress-mediated neurodegeneration. ${ }^{40,41}$ These combined results indicate that GRP78 may be increased early after infection, but, under the conditions of prolonged ER stress in late stages of diseases, the induction of GRP78 may not be as efficient as those of other ER stress markers. Such levels of GRP78 induction may not be sufficient to protect neurons against ER stress in $t s 1-$, FrCas $^{\mathrm{E}_{-}}$, or scrapie-infected mice, since GRP78 overexpression protects cellular death under ER stress conditions by stabilizing $\mathrm{Ca}^{2+}$ homeostasis. ${ }^{47,48}$

The activation of caspase- 12 is a crucial event in ER stress-mediated cell death. ${ }^{20}$ In ts1-infected 


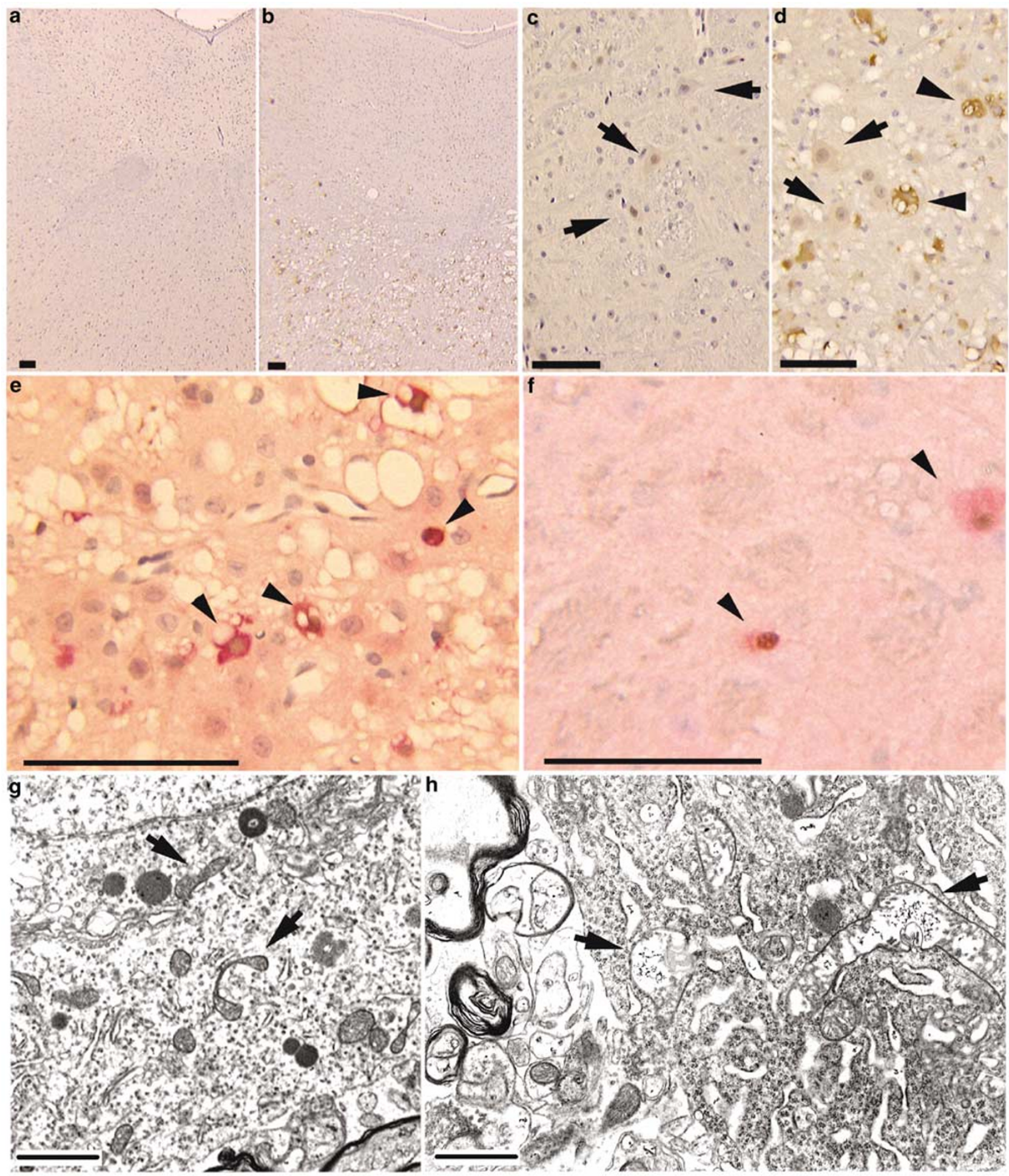

Figure 7 Increased expression of p-CaMKII- $\alpha$ protein and $\mathrm{Ca}^{2+}$ deposits in neurons of brainstems of $t s 1$-infected mice. (a) p-CaMKII- $\alpha$ immunoreactivity (brown) in brainstem from a control mouse. (b) p-CaMKII- $\alpha$ immunoreactivity in $t s 1$-infected brainstem at 25 dpi. (c) Higher magnification view of the neuronal cells (arrows) in panel (a). Note the absent or very weak cytoplasmic staining in neurons (arrows). (d) Higher magnification views of the neuronal cells in panel (b). Note the strong staining in neurons undergoing degenerative changes such as vacuolization (arrowheads) and the weak immunoreactivity in neurons with normal appearance (arrows). (e. $\mathbf{f}$ ) Coexpression of GADD153/CHOP (brown, nuclei) and p-CaMKII $\alpha$ (red, cytoplasm) in the neurons (arrowheads) in ts1-infected brainstem at $25 \mathrm{dpi}(\mathbf{e})$ and $20 \mathrm{dpi}(\mathbf{f})$. Bars indicate $200 \mu \mathrm{m}$. (g, h) Electron micrograph showing dense granular $\mathrm{Ca}^{2+}$ pyroantimonate deposits in mitochondria of neurons (arrows) from ts1-infected brainstem at $20 \mathrm{dpi}$ (h). Note the absence of granular deposits in mitochondria of neurons (arrows) from control (g). Bars indicate $3 \mu \mathrm{m}$. 
brainstem tissue, expression and activation of caspase- 12 are increased, and this is accompanied by increases in cleavage activation of its downstream target, caspase-3. This cleaved caspase- 3 is the caspase most frequently reported to participate in neuronal cell death. Interestingly, increase in caspase-12 protein was correlated with increased amounts of caspase-12 mRNA. This induction may be due to expression of interferon- $\gamma$ induced during ts1 infection, as demonstrated by recent publications that either interferon- $\gamma$ alone or in concert with TNF- $\alpha$, is capable of activating the transcription of caspase-12 gene as well as the processing of caspase$12.49,50$

Previous studies have shown that the $\mathrm{ER} \mathrm{Ca}^{2+}$ ATPase inhibitor Thapsigarin, or $\mathrm{Ca}^{2+}$ ionopores induce transcriptional activation of GADD153/ CHOP by elevating intracellular $\mathrm{Ca}^{2+} .{ }^{35,51}$ We therefore attempted to dissect the mechanism of induction of ER stress signaling pathway in ts1-infected brainstems by investigating $\mathrm{Ca}^{2+}$ signaling pathways. In this study, we found that phosphorylation of CaMKII- $\alpha$ is increased and that phosphorylated CaMKII- $\alpha$ is present, together with GADD153/CHOP and cleaved caspase-3, in most neurons in brainstems from both early and advanced stages of the disease (Figures 6 and 7). This result suggests that perturbation of $\mathrm{Ca}^{2+}$ homeostasis is a potential mechanism responsible for induction of ER stress in neurons. This notion is supported by electron microscopic evidence of increased intracellular $\mathrm{Ca}^{2+}$, manifested as $\mathrm{Ca}^{2+}$ precipitates in the mitochondria in neurons during early stages (Figure 7 ).

One key issue that should be addressed is what types of cells in brainstems are specially affected by ER stress. We have obtained immunohistological data showing the induction of ER stress markers in neurons, but not in glial cells (Figures 3, 5, and 7). Involvement of ER stress in neurons is further supported by observation of increase in intracellular $\mathrm{Ca}^{2+}$ (Figure 7). These results suggest that activation of ER stress signaling pathways in neurons are likely due to an indirect mechanism(s), since our previous work has revealed that $t s 1$ virus infects glial cells, but not neurons. ${ }^{5}$ Therefore, the present study strongly indicates that ER stress-mediated spongiform neurodegeneration is likely to be caused by neurotoxic products secreted from glial cells by $t s 1$ infection.

Among the elements present within the lesions of the ts1-infected brainstem, TNF- $\alpha$ and NO are probably prime candidates as triggers for ER stress in neurons, since both are upregulated in astrocytes by $t s 1$ infection. ${ }^{6,7}$ These agents may cause ER $\mathrm{Ca}^{2+}$ release in surrounding neurons, leading to activation of ER stress signaling pathways, as demonstrated by previous reports. ${ }^{2-24}$ Also, TNF- $\alpha$ may cause glutamate accumulation in the vicinity of neurons, which activates $N$-methyl-D-aspartate (NMDA) receptor-operated channels on the neuronal surface, causing $\mathrm{Ca}^{2+}$ influx and activation of
CaMKII, ${ }^{52,53}$ as shown in Figure 7. This notion is supported by recent reports that excitotoxicity associated with NMDA receptor induces GADD153/CHOP production, and activation and phosphorylation of CaMKII- $\alpha$, leading to neuronal death. ${ }^{54-56}$

In conclusion, we show here that activation of ER stress signaling pathways constitutes a sequential and inter-related cytotoxic signaling cascade that causes neuronal injury in the ts1-infected brainstem. The potential importance of the $\mathrm{Ca}^{2+}$-ER stress link in the pathogenesis of spongiform encephalopathy by $t s 1$ infection, particularly neuronal degeneration, is now evident. Furthermore, the data presented here support the idea that ER stress-mediated neurodegeneration is likely to be caused by neurotoxic products secreted from glial cells by ts 1 infection.

\section{Acknowledgements}

This work was supported in part by grants to PKY Wong from the NIH (AI28283 and NS43984). We thank Vanessa Edwards for her assistance in preparing the manuscript.

\section{References}

1 Yuen PH, Szurek PF. The reduced virulence of the thymotropic Moloney murine leukemia virus derivative MoMuLV-TB is mapped to 11 mutations within the U3 region of the long terminal repeat. J Virol 1989;63:471-480.

2 Wong PKY, Prasad G, Hansen J, et al. ts1, a mutant of Moloney murine leukemia virus-TB, causes both immunodeficiency and neurologic disorders in BALB/c mice. Virology 1989;170:450-459.

3 Szurek PF, Yuen PH, Ball JK, et al. A Val-25-to-Ile substitution in the envelope precursor polyprotein, gPr80env, is responsible for the temperature sensitivity, inefficient processing of gPr80env, and neurovirulence of ts1, a mutant of Moloney murine leukemia virus TB. J Virol 1990;64:467-475.

4 Wong PKY, Floyd E, Szurek PF. High susceptibility of FVB/N mice to the paralytic disease induced by ts1, a mutant of Moloney murine leukemia virus TB. Virology 1991;180:365-371.

5 Stoica G, Illanes O, Tasca SI, et al. Temporal central and peripheral nervous system changes induced by a paralytogenic mutant of Moloney murine leukemia virus TB. Lab Invest 1993;69:724-735.

6 Choe W, Stoica G, Lynn W, et al. Neurodegeneration induced by MoMuLV-ts1 and increased expression of Fas and TNF- $\alpha$ in the central nervous system. Brain Res 1998;779:1-8.

7 Kim HT, Qiang W, Wong PKY, et al. Enhanced proteolysis of $\mathrm{I} \kappa \mathrm{B} \alpha$ and $\mathrm{I} \kappa \mathrm{B} \beta$ proteins in astrocytes by Moloney murine leukemia virus (MoMuLV)-ts1 infection: A potential mechanism of $\mathrm{NF}-\kappa \mathrm{B}$ activation. J Neurovirol 2001;7:466-475

8 Stoica G, Tasca SI, Wong PKY. Motor neuronal loss and neurofilament-ubiquitin alteration in MoMuLV-ts1 
encephalopathy. Acta Neuropathol (Berl) 2000;99: 238-244.

9 Tyor WR, Wesselingh SL, Griffin JW, et al. Unifying hypothesis for the pathogenesis of HIV-associated dementia complex, vacuolar myelopathy, and sensory neuropathy. J Acquir Immune Defic Syndr Hum Retrovirol. 1995;9:379-388.

10 Forno LS. Neuropathology of Parkinson's disease. J Neuropathol Exp Neurol 1996;55:259-272.

11 Tu PH, Raju P, Robinson KA, et al. Transgenic mice carrying a human mutant superoxide dismutase transgene develop neuronal cytoskeletal pathology resembling human amyotrophic lateral sclerosis lesions. Proc Natl Acad Sci USA 1996;93:3155-3160.

12 Sagot Y, Dubois-Dauphin M, Tan SA, et al. Bcl-2 overexpression prevents motoneuron cell body loss but not axonal degeneration in a mouse model of a neurodegenerative disease. J Neurosci 1995;15: 7727-7733.

13 Prusiner SB. Prions. Proc Natl Acad Sci USA 1998;95:13363-13383.

14 Harding HP, Zhang Y, Ron D. Protein translation and folding are coupled by an endoplasmic reticulumresident kinase. Nature 1999;397:271-274.

15 Kaufman RJ. Stress signaling from the lumen of the endoplasmic reticulum: coordination of gene transcriptional and translational controls. Genes Dev 1999;13:1211-1233.

16 Paschen W. Dependence of vital cell function on endoplasmic reticulum calcium levels: implications for the mechanisms underlying neuronal cell injury in different pathological states. Cell Calcium 2001;29: $1-11$.

17 Ron D, Habener JF. CHOP, a novel developmentally regulated nuclear protein that dimerizes with transcription factors C/EBP and LAP and functions as a dominant-negative inhibitor of gene transcription. Genes Dev 1992;6:439-453.

18 Barone MV, Crozat A, Tabaee A, et al. CHOP (GADD153) and its oncogenic variant, TLS-CHOP, have opposing effects on the induction of G1/S arrest. Genes Dev 1994;8:453-464.

19 Fawcett TW, Eastman HB, Martindale JL, et al. Physical and functional association between GADD153 and CCAAT/enhancer-binding protein $\beta$ during cellular stress. J Biol Chem 1996;271:14285-14289.

20 Nakagawa T, Zhu H, Morishima N, et al. Caspase-12 mediates endoplasmic-reticulum-specific apoptosis and cytotoxicity by amyloid-beta. Nature 2000;403: 98-103.

21 Sherman MY, Goldberg AL. Cellular defenses against unfolded proteins: a cell biologist thinks about neurodegenerative diseases. Neuron 2001;29:15-32.

22 Oyadomari S, Takeda K, Takiguchi M, et al. Nitric oxide-induced apoptosis in pancreatic beta cells is mediated by the endoplasmic reticulum stress pathway. Proc Natl Acad Sci USA 2001;98:10845-10850.

23 Gotoh T, Oyadomari S, Mori K, et al. Nitric oxideinduced apoptosis in RAW 264.7 macrophages is mediated by endoplasmic reticulum stress pathway involving ATF6 and CHOP. J Biol Chem 2002;277: 12343-12350.

24 Kim BC, Kim HT, Mamura M, et al. Tumor necrosis factor induces apoptosis in hepatoma cells by increasing $\mathrm{Ca}(2+)$ release from the endoplasmic reticulum and suppressing Bcl-2 expression. J Biol Chem 2002; 277:31381-31389.
25 Hacki J, Egger L, Monney L, et al. Apoptotic crosstalk between the endoplasmic reticulum and mitochondria controlled by Bcl-2. Oncogene 2000;19: 2286-2295.

26 Wei MC, Zong WX, Cheng EH, et al. Proapoptotic BAX and BAK: a requisite gateway to mitochondrial dysfunction and death. Science 2001;292:727-730.

27 Desagher S, Martinou JC. Mitochondria as the central control point of apoptosis. Trends Cell Biol 2000;10: 369-377.

28 Kim HT, Tasca S, Qiang W, et al. Induction of p53 accumulation by Moloney murine leukemia virus-ts1 infection in astrocytes via activation of extracellular signal-regulated kinases 1/2. Lab Invest 2002;82: 693-702.

29 Wong PKY, Soong MM, Yuen PH. Replication of murine leukemia virus in heterologous cells: interaction between ecotropic and xenotropic viruses. Virology 1981;109:366-378.

$30 \mathrm{Kim}$ HT, Stoica G, Bazer FW, et al. Interferon tauinduced hepatocyte apoptosis in sheep. Hepatology 2000;31:1275-1284.

31 Siklos L, Engelhardt JI, Reaume AG, et al. Altered calcium homeostasis in spinal motoneurons but not in oculomotor neurons of SOD-1 knockout mice. Acta Neuropathol 2000;99:517-524.

32 Gonzales-Scarano F, Nathanson N, Wong PKY. Retroviruses and the nervous system. In: Levy JA (ed). The Retroviridae. Plenum Press: New York, 1995, pp 127-136.

33 Earnshaw WC, Martins LM, Kaufmann SH. Mammalian caspases: structure, activation, substrates, and functions during apoptosis. Annu Rev Biochem 1999;68:383-424.

34 Rao RV, Castro-Obregon S, Frankowski H, et al. Coupling endoplasmic reticulum stress to the cell death program. An Apaf-1-independent intrinsic pathway. J Biol Chem 2002;277:21836-21842.

35 Bartlett JD, Luethy JD, Carlson SG, et al. Calcium ionophore A23187 induces expression of the growth arrest and DNA damage inducible CCAAT/enhancerbinding protein (C/EBP)-related gene, gadd153. $\mathrm{Ca}^{2+}$ increases transcriptional activity and mRNA stability. J Biol Chem 1992;267:20465-20470.

36 Lipton SA, Nicotera P. Calcium, free radicals and excitotoxins in neuronal apoptosis. Cell Calcium 1997;23:165-171.

37 Orrenius S, Zhivotovsky B, Nicotera P. Regulation of cell death: the calcium-apoptosis link. Nat Rev Mol Cell Biol 2003;4:552-565.

38 Braun AP, Schulman H. The multifunctional calcium/ calmodulin-dependent protein kinase: from form to function. Annu Rev Physiol 1995;57:417-445.

39 Soderling TR. The Ca-calmodulin-dependent protein kinase cascade. Trends Biochem Sci 1999;24: 232-236.

40 Hetz C, Russelakis-Carneiro M, Maundrell K, et al. Caspase-12 and endoplasmic reticulum stress mediate neurotoxicity of pathological prion protein. EMBO J 2003;22:5435-5445.

41 Dimcheff DE, Askovic S, Baker AH, et al. Endoplasmic reticulum stress is a determinant of retrovirus-induced spongiform neurodegeneration. J Virol 2003;77: 12617-12629.

42 Spear E, Ng DT. The unfolded protein response: no longer just a special teams player. Traffic 2001;2: 515-523. 
43 McCullough KD, Martindale JL, Klotz LO, et al. Gadd153 sensitizes cells to endoplasmic reticulum stress by down-regulating Bcl2 and perturbing the cellular redox state. Mol Cell Biol 2001;21:1249-1259.

44 Boya P, Cohen I, Zamzami N, et al. Endoplasmic reticulum stress-induced cell death requires mitochondrial membrane permeabilization. Cell Death Differ 2002;9:465-467.

45 Zong WX, Li C, Hatzivassiliou G, et al. Bax and Bak can localize to the endoplasmic reticulum to initiate apoptosis. J Cell Biol 2003;162:59-69.

46 Liu H, Bowes III RC, van de Water B, et al. Endoplasmic reticulum chaperones GRP78 and calreticulin prevent oxidative stress, $\mathrm{Ca}^{2+}$ disturbances, and cell death in renal epithelial cells. J Biol Chem 1997;272:21751-21759.

47 Morris JA, Dorner AJ, Edwards CA, et al. Immunoglobulin binding protein $(\mathrm{BiP})$ function is required to protect cells from endoplasmic reticulum stress but is not required for the secretion of selective proteins. J Biol Chem 1997;272:4327-4334.

$48 \mathrm{Yu} \mathrm{Z}$, Luo H, Fu W, et al. The endoplasmic reticulum stress-responsive protein GRP78 protects neurons against excitotoxicity and apoptosis: suppression of oxidative stress and stabilization of calcium homeostasis. Exp Neurol 1999;155:302-314.

49 Kalai M, Lamkanfi M, Denecker G, et al. Regulation of the expression and processing of caspase-12. J Cell Biol 2003;162:457-467.
50 Watanabe Y, Suzuki O, Haruyama T, et al. Interferongamma induces reactive oxygen species and endoplasmic reticulum stress at the hepatic apoptosis. J Cell Biochem 2003;89:244-253.

51 Thastrup O, Cullen PJ, Drobak BK, et al. Thapsigargin, a tumor promoter, discharges intracellular $\mathrm{Ca} 2+$ stores by specific inhibition of the endoplasmic reticulum Ca2(+)-ATPase. Proc Natl Acad Sci USA 1990;87:2466-2470.

52 Fine S M, Angel RA, Perry SW, et al. Tumor necrosis factor- $\alpha$ inhibits glutamate uptake by primary human astrocytes: implications for pathogenesis of HIV-1 dementia. J Biol Chem 1996;271: 15303-15306.

53 Bezzi P, Domercq M, Brambilla L, et al. CXCR4activated astrocytes glutamate release via $\mathrm{TNF} \alpha$ : amplification by microglia triggers neurotoxicity. Nat Neurosci 2001;4:702-710.

54 Laabich A, Li G, Cooper NG. Characterization of apoptosis-genes associated with NMDA mediated cell death in the adult rat retina. Brain Res Mol Brain Res 2001;91:34-42.

55 Foos TM, Wu JY. The role of taurine in the central nervous system and the modulation of intracellular calcium homeostasis. Neurochem Res 2002;27:21-26.

56 Takano H, Fukushi H, Morishima Y, et al. Calmodulin and calmodulin-dependent kinase II mediate neuronal cell death induced by depolarization. Brain Res 2003;962:41-47. 